\title{
Information technology in university-level mathematics teaching and learning: a mathematician's point of view
}

\author{
Alexandre Borovik* \\ School of Mathematics, University of Manchester, Manchester, UK
}

(Received 26 July 2010; final version received 18 November 2010)

\begin{abstract}
Although mathematicians frequently use specialist software in direct teaching of mathematics, as a means of delivery e-learning technologies have so far been less widely used. We (mathematicians) insist that teaching methods should be subjectspecific and content-driven, not delivery-driven. We oppose generic approaches to teaching, including excessively generalist, content-free, one-size-fits-all promotion of information and communications technology. This stance is fully expressed, for example, in the recent Teaching Position Statement from the London Mathematical Society (2010) and is supported by a recent report from the National Union of Students $(2010,5)$ : "Not every area of study needed or was compatible with e-learning, and so to assume it would grant blanket advantages was not accurate". This paper is an attempt to explain mathematicians' selectivity in use of information and communications technology and its guiding principles. The paper is addressed to our non-mathematician colleagues and is not intended to be a survey of the existing software and courseware for mathematics teaching - the corpus of existing solutions is enormous and its discussion inevitably involves hardcore mathematics.
\end{abstract}

Keywords: mathematics; university; information technology

\section{Selectivity: why?}

I argue that mathematics deserves special treatment not only because of its highly specific cognitive nature, but also because the mathematics community has accumulated much more experience of using computers and information technology (IT) in teaching, learning, research and communication than many of our colleagues outside STEM (science, technology, engineering and mathematics) disciplines have attained in their considerably shorter exposure to IT. We are not special: computer science, physics, and many engineering disciplines are in a similar position and should be trusted to use their own tried and tested approaches to IT.

Historically, mathematicians (and computer scientists) were the first to use IT in teaching. Even in the era of mainframe computers, green displays and dot-matrix printers, some serious work was done in that area (e.g. mass generation of random problems of controlled level of difficulty in linear algebra and differential equations).

University mathematicians (and not only researchers, but all mathematicians who teach all kinds of mathematics in universities) form a professional community; it is global and transcends national boundaries. Yes, mathematicians were some of the first

*Email: borovik@manchester.ac.uk 
to use email, too - at the time when the Internet existed as a set of ftp sites and was unknown outside mathematics, physics and computer science departments.

In short, the mathematics community has experience and knowledge of what can and cannot be done with computers. In that respect, we differ from, say, our colleagues in the humanities who are still on a path of discovery. I sincerely hope that IT solutions that do not work in mathematics teaching can be happily used, say, in the humanities or in the social sciences - but please do not force on us solutions unsuitable for, and unworkable in, mathematics learning and teaching.

\section{A case study: $T e X$}

In the late 1970s, the great mathematician and computer scientist Donald Knuth launched a revolution in scientific communication by creating TeX, a cross-platform computer language for typesetting mathematical texts (Knuth 1979, 1986a). In one step, he brought mundane mathematical scribbles - not only research papers, but also lecture notes, exercise sheets, seminar handouts - to the highest reaches of typographic art. Since the early 1990s, TeX and its dialect, LaTeX (Lamport 1985), have been international standards for mathematical typesetting. However, their routine everyday use in teaching in every mathematics department remains unnoticed and unappreciated by the wider education community. This is unfortunate because TeX/ LaTeX is a pedagogical success story: it allows the presentation of even the most complicated mathematical formulae as structured and logically justified shapes, optimised for visual processing by the human eye and brain. After all:

Typography may be defined as the craft of rightly disposing printing material in accordance with specific purpose; of so controlling the type as to aid to the maximum the reader's comprehension of the text. (Morison 1951; quoted from Lawrence 2003, 165)

TeX succeeded in part because Donald Knuth spent years studying the tradition of calligraphy (worth remembering - it is millennia long) and the art of typesetting (five centuries old) (Knuth 1999). In the process, Knuth produced such masterpieces as 3:16 Bible Texts Illuminated (Knuth 1990) with 60 original illustrations by many of the world's leading calligraphers.

Speaking about software systems for teaching and learning that are currently commercially available in the higher education market, we can safely conclude that in $95 \%$ of IT products the presentation of mathematics lags 20 years behind TeX; their developers have not done their homework with the same care as Donald Knuth did his. Too frequently, IT developers and promoters of e-learning invite mathematicians back to the Stone Age.

For those who have never seen how LaTeX typesets mathematical formulae, Figure 1 contains a few random examples set in font type, size, and column width suitable for viewing on narrow screens of smart phones (some of my students indeed use their smart phones for access to bite-sized learning materials like exercise sheets - although smart phones are not very convenient for reading more substantial pieces of text like lecture notes). Figure 2 shows how LaTeX handles difficult spatial arrangements of type.

For dyslexic students, one can easily meet disability consultants' recommendations by setting up lecture notes in landscape mode, double-line spacing and a huge sans serif font (Figure 3). 


\section{Here is Schrödinger's Equation:}

$$
i \hbar \frac{\partial}{\partial t} \Psi=\hat{H} \Psi
$$

and here is Stokes' Theorem:

$$
\int_{\Omega} d \omega=\oint_{\partial \Omega} \omega,
$$

and this is an infinite product expansion for the Gamma function:

$$
\begin{aligned}
\Gamma(z) & =\lim _{n \rightarrow \infty} \frac{n ! n^{z}}{z(z+1) \cdots(z+n)} \\
& =\frac{1}{z} \prod_{n=1}^{\infty} \frac{\left(1+\frac{1}{n}\right)^{z}}{1+\frac{z}{n}} .
\end{aligned}
$$

Figure 1. A sample of LaTeX output optimised for viewing on a smart phone screen.

\section{Students matter}

I have taught computer-based courses since 1995 - and I had a chance to observe my students in pedagogical and psychological mise en scènes of information and communications technology (ICT).

Studies of students' attitudes to IT already exist, and the Association for Learning Technology (2010) provides a useful survey. A recent report from the National Union of Students (2010) expresses a summarised students' opinion in a very direct and unambiguous way. I quote two points that match my personal observations. One point is that students want to have choice and want to be in control: 


\section{The following two formulae for the Golden Ratio show how LATEX handles nested roots:}

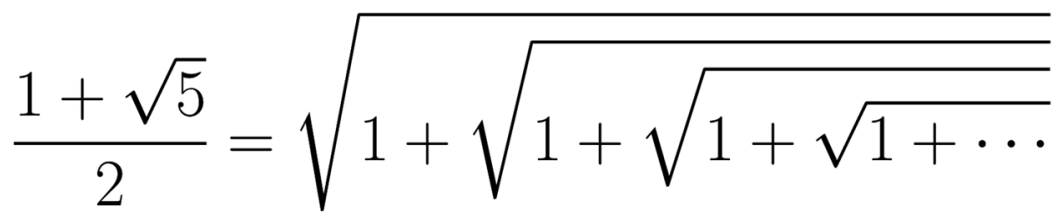

\section{and continued fractions:}

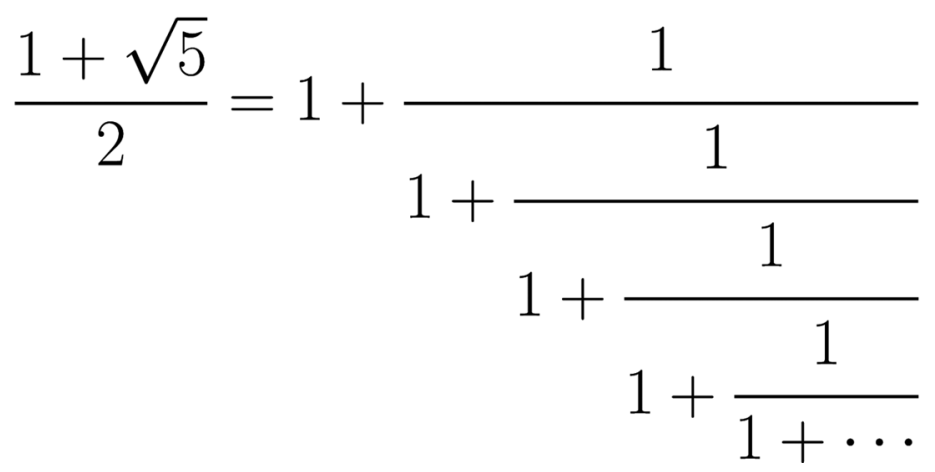

Figure 2. LaTeX: handling of nested roots and continued fractions.

Students prefer a choice in how they learn - ICT is seen as one of many possibilities, alongside part-time and traditional full-time learning, and face-to-face teaching. (National Union of Students 2010, 3)

Students could see some advantages to an e-learning approach. If it were presented as an option, as opposed to an obligation, it would avoid onerous undertones. (National Union of Students 2010, 5)

$$
\Gamma(z)=\frac{1}{z} \prod_{n=1}^{\infty} \frac{\left(1+\frac{1}{n}\right)^{z}}{1+\frac{z}{n}} .
$$

Figure 3. An example of typesetting of formulae adjusted for needs of dyslexic readers. 
Students who preferred or were most familiar with traditional lecturing methods also might feel cheated if the course was provided mainly online. (National Union of Students 2010, 26)

Another point is that content matters for students more than delivery:

Participants expressed concerns over 'surface learning' whereby a student only learns the bare minimum to meet module requirements - this behaviour was thought to be encouraged by ICT: students can easily skim-read material online, focusing on key terms rather than a broader base of understanding. (National Union of Students 2010, 5)

Students matter, and their opinion should matter, too.

\section{What we want: windows in mathematical world}

Let me formulate in one word the shared key feature of IT that finds modern uses in direct teaching of mathematics: this word is virtualisation. A computer is useful if it creates a new (virtual) reality that cannot be created by other means. In mathematics, the word 'reality' includes the ideal Platonic world of mathematical objects and structures. Matlab, ${ }^{1}$ Maple, Mathematica - commercial (and expensive) mathematics software packages widely used in undergraduate teaching - are windows into this Platonic world. As a rule, software that provides such windows needs a powerful mathematical engine. Matlab, Maple, Mathematica and statistics packages such as SPSS (commercial) and R (open source and free) are not just toys for learning - they are professional research tools; mastering them is a valuable transferable skill for graduates seeking employment in mathematics-intensive industries.

I can give less known and more specialised examples, like Tarski's World - an expertly crafted courseware package for learning mathematical logic (Barwise and Etchemendy 1993); an improved version is now available under the same title (Barker-Plummer, Barwise, and Etchemendy 2008) and the wonderful visualisation and experimentation tools for elementary geometry, Cinderella ${ }^{2}$ and GeoGebra. ${ }^{3}$

Assessment of mathematics learning software inevitably involves a mathematical characterisation of its built-in mathematical world. For example, it matters that the interface language of Tarski's World is 'interpreted' (in some specific meaning of this word as used in logic) - and serious implications of this fact for teaching logic with Tarski's World had been pointed out in one of the first reviews of the package (Hodges 1989) - written in 1989!

If the reader wishes to get hands-on experience, I invite him/her to have a look at Cinderella and GeoGebra - they are available for free, and their uncluttered minimalistic interfaces provide for an immediate usability; because of space limitations, I can only mention in passing commercial dynamic geometry packages (Cabri, Geometer's Sketchpad). The next two paragraphs use Cinderella and GeoGebra to give a sample of a mathematician's approach to probing and testing the software; they can be skipped in the first reading.

It is interesting to compare the behaviour, in Cinderella and GeoGebra, of a simple interactive diagram: two intersecting circles of varying radii and the straight line determined by their points of intersection (see Figure $4 \mathrm{a}$ for a Cinderella snapshot). In GeoGebra, when you vary the radii or move the centres of the circles and make the circles non-intersecting, the line through the points of intersection disappears - exactly as one should expect (Figure 5). In Cinderella, the line does not disappear, it moves 
(a)

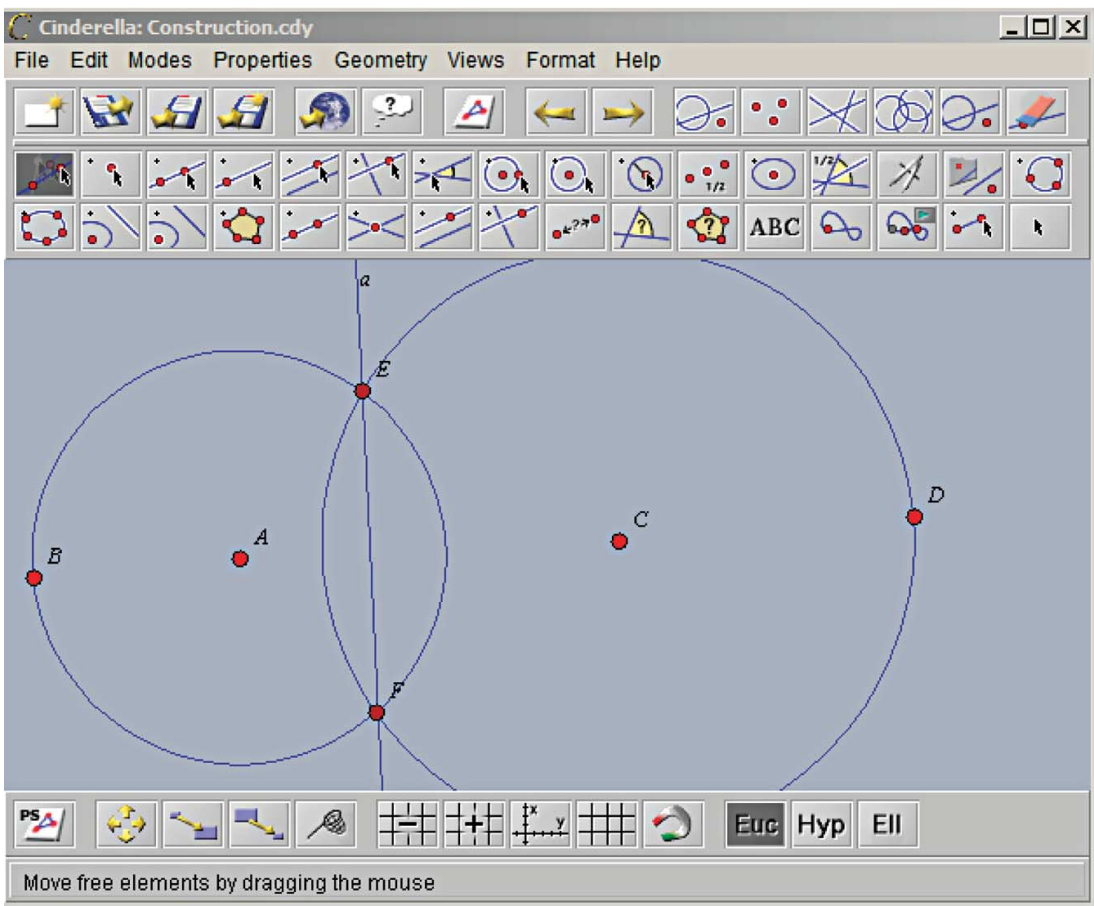

(b)

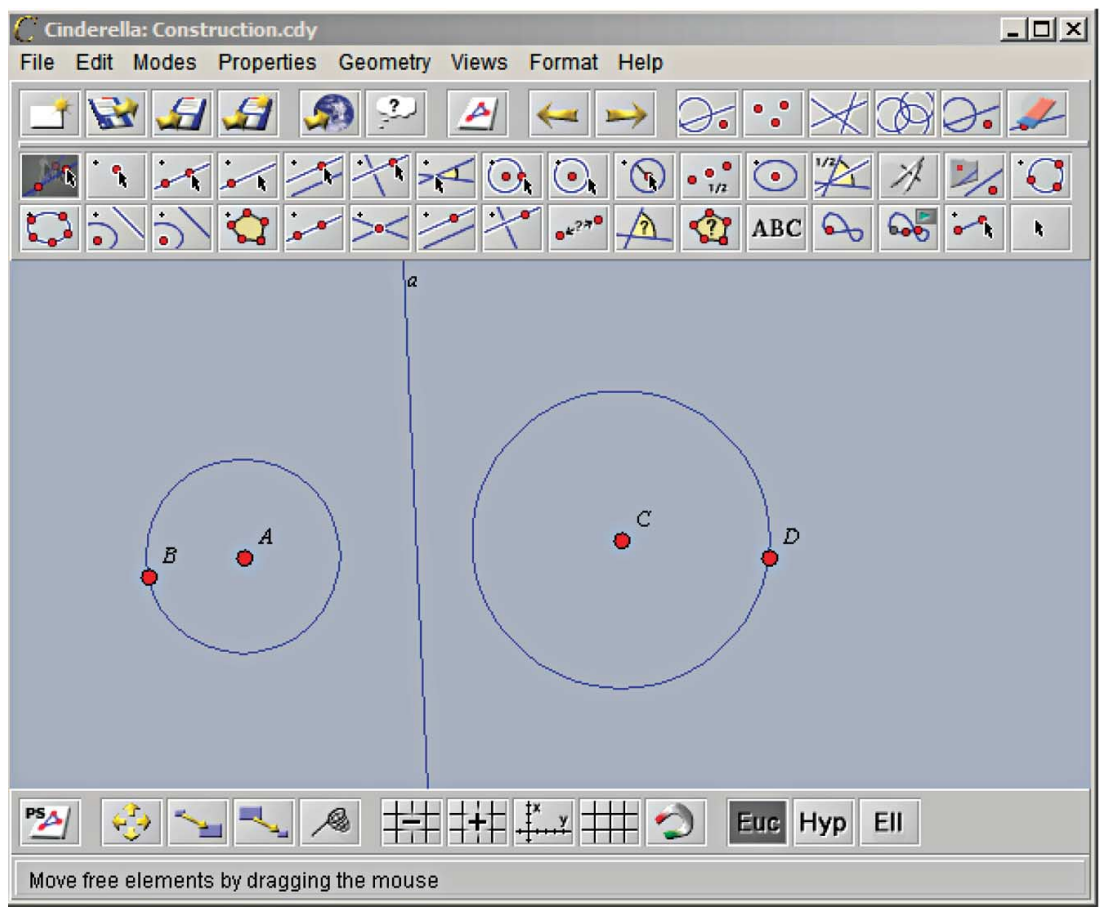

Figure 4. Cinderella: (a) a line through the intersection points of two circles; (b) the line through the intersection points of two circles does not disappear after the circles are disengaged. 


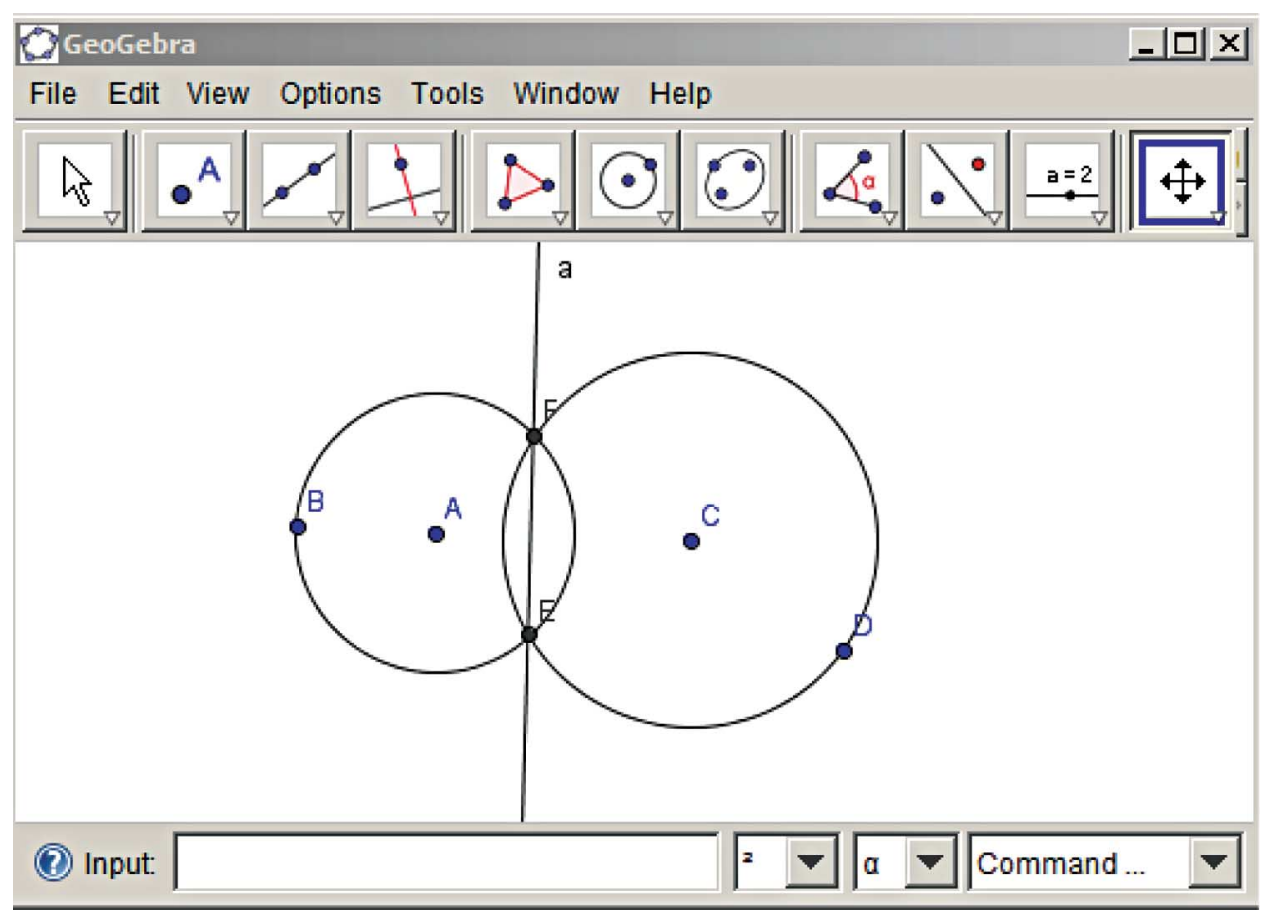

Figure 5. GeoGebra: (a) a line through the intersection points of two circles; (b) the line through the intersection points of two circles disappeared after the circles are disengaged.

following the movements of the circles, always separating them (Figure 4b); when circles touch each other and start to intersect again, the line turns to be, again, the common tangent line of two circles or, in the case of two intersecting circles, the line through the points of intersection. (The line is called the radical axis of the two circles.)

To a mathematician, the behaviour of this diagram suggests that the underlying mathematical structure of GeoGebra is the real Euclidean plane. In Cinderella, the underlying structure is the complex projective plane; what we see on the screen is just a tiny fragment of it, a real affine part. The radical axis of two non-intersecting circles is the real part of the complex line through two complex points of intersection. The intersection points of two real circles are complex conjugate, the line is invariant under complex conjugation and therefore is real and shows up on the real Euclidean plane. For a mathematician, this is a strong hint that Cinderella could work better than GeoGebra in accommodating non-Euclidean geometries: elliptic and hyperbolic (the Lobachevsky plane) since they happily live in the complex projective plane. But perhaps there may be pedagogic situations where the real Euclidean plane might be a safer tool for some students than the complex projective plane, even if the difference is undetectable at the first glance.

\section{The unity of research and teaching}

One interesting feature of Matlab, Maple, Mathematica and SPSS is that they were originally designed and developed for research purposes and only later fed into university teaching - mostly by mathematicians who transferred to their teaching the 
skills developed in their research. It was the mathematics research community who acted as a driver of technological change in mathematics teaching. This example, even taken on its own, demonstrates the futility of erecting a fence between mathematics research and mathematics teaching.

The situation with specialised teaching-only software packages is even more instructive. Returning to one of my case studies, Tarski's World, I wish to comment that one of its authors - and the initiator of the project - was Kenneth Jon Barwise, a prominent mathematician, philosopher and logician.

Development of Tarski's World and other programs that became part of the courseware package Language, Proof and Logic (Barwise and Etchemendy 2003): Fitch, Boole, Grade Grinder, required not only a pioneering re-assessment of methodology of teaching mathematical logic (Barwise and Etchemendy 1998), but also the creation of a new direction in mathematical logic itself, heterogeneous reasoning, which formed the core of the computer algorithms implemented as courseware (Shin 2004). The first reviewers of Tarski's World (Boolos 1990; Goldson and Reeds 1993) were fully aware of mathematical difficulties that its authors had to overcome.

The work of Jon Barwise and his collaborators is a manifestation of a phenomenon specific to mathematics: the central role of didactic transformation; that is, mathematical reworking of teaching material into a form suitable for students' consumption. The term transformation didactique was coined in 1852 by French philosopher Auguste Comte (1852) and is well known in French education studies (Chevallard 1985), but remains unused in English-language literature on education. Hyman Bass, a prominent mathematician and a champion of mathematics education, picked up from his French colleague Jean-Pierre Kahane (Bass 2005) the term 'didactic transformation' together with an explanation of its role in relations between mathematics and mathematics education:

In no other living science is the part of presentation, of the transformation of disciplinary knowledge to knowledge as it is to be taught (transformation didactique) so important at a research level.

In no other discipline, however, is the distance between the taught and the new so large. In no other science has teaching and learning such social importance.

In no other science is there such an old tradition of scientists' commitment to educational questions. (Bass 2005)

In Barwise's case, didactic transformation took the form of mathematical research in logic that was then fed into software development.

Even the roots of dynamic geometry packages aimed at the teaching of elementary Euclidean geometry can be traced back to the hard core research. This is a testimony from Judah Schwartz, creator (in early 1980s) of one of the first interactive geometry packages, The Geometric Supposer:

In the mid-1960s, while on the research staff of the Lawrence Radiation Laboratory in California, two colleagues and I developed a series of computer-generated motion picture films that depicted graphically the collisions of subatomic particles as described by formal mathematical machinery of quantum mechanics. I became interested in the potential of the computer to make accessible representations of spatial and temporal whose natural distance and time scale lay well outside the ken of human sensory apparatus. My colleagues and I pursued these efforts for a while but soon concluded that the true utility of computers to help people with mathematical abstraction would lie in the interactivity and control that the soon-to-come microcomputer would offer. (Schwartz, Yerushalmy, and Wilson 1993, 4) 


\section{Paradoxical economics of education}

So mathematicians have developed, and systematically use, specialist software in direct teaching of mathematics - and find it very useful.

However, as means of delivery of mathematics teaching, IT and e-learning have so far been unable to meet our expectations. There are several reasons for this.

One reason is that our expectations are high. Due to the level of sophistication already achieved, say, in Matlab/Mathematica/Maple or in TeX/LaTeX, mathematicians' demands for functionality of IT are high and are not met by many software packages and virtual learning environments (VLEs) currently promoted in British universities.

At a neurophysiological level, teaching/learning mathematics is a communication between two brains. It is best done one-to-one, or in a small group. Large class lectures are an unhappy compromise with economic necessity. From a pedagogical point of view, the right alternative to a large class lecture is not streaming-on-demand of video recordings; the true alternative is a small class lecture. Unfortunately, this alternative in most cases is financially infeasible. Collaborative online small groups provide some interesting possibilities, but students themselves insist that ICT should be a supplement to, not a replacement of, face-to-face teaching:

Motion 306, passed at the April 2010 NUS National Conference states that: [-]

4. The provision of e-learning should be utilised as a tool for learning, in all institutions, but that should not merely be used as a method of reducing costs and should be in conjunction with, not instead of, other face-to-face teaching methods.

5. Technology should complement good teaching, allowing students to benefit from the additional value of e-learning but should not be used as a substitute for face-to-face contact and good teaching. (National Union of Students, 2010, 18)

There is a need to assess the efficiency of particular methods of teaching not only from the pedagogical, but also from a socio-economic point of view. Of course, 'generic' technologies are very tempting to policy-makers because of their promise (mostly unrealistic) of economies of scale. It would be wrong to reduce the all-important discussion of learning and teaching to deciding the choice of the cheapest variety of margarine as a substitution for butter.

Last but not least, at the socio-economic level relations between mathematics and information technology are also paradoxical.

Mathematics, by its nature, is an open source phenomenon. A powerful formulation of this principle belongs to Joachim Neubüser, the initiator and leader of the GAP project, ${ }^{4}$ perhaps the most successful community project in experimental mathematics.

You can read Sylow's Theorem and its proof in Huppert's book in the library without even buying the book and then you can use Sylow's Theorem for the rest of your life free of charge, but - and for understandable reasons [...] - for many computer algebra systems license fees have to be paid regularly for the total time of their use. In order to protect what you pay for, you do not get the source, but only an executable, i.e. a black box. You can press buttons and you get answers in the same way as you get the bright pictures from your television set but you cannot control how they were made in either case.

With this situation two of the most basic rules of conduct in mathematics are violated: In mathematics information is passed on free of charge and every thing is laid open for 
checking. Not applying these rules to computer algebra systems [...] means moving in a most undesirable direction. Most important: Can we expect somebody to believe a result of a program that he is not allowed to see? (Neubüser 1993)

It is almost a rule that open source software systems are friendlier to mathematics; perhaps this could be explained by the social and cultural background of the open source movement; Neubüser's words "Can we expect somebody to believe a result of a program that he is not allowed to see?" is a war cry and a cultural paradigm shared by mathematicians (who apply it, in the first instance, to proofs of their theorems) and by open source warriors. A good illustration of this principle can be found in a comparison between Moodle, a free open source VLE (it provides for a decent rendering of LaTeX), and proprietary VLEs, some of which are completely unfit for use in mathematics courses.

Developers of quality proprietary software for mathematics and statistics (like Matlab/Mathematica/Maple, SPSS) have taken reasonable care to allow the users a sufficient degree of freedom in tinkering with the interface (and, at least in the case of Matlab - with the computational core, too - Matlab smoothly incorporates bespoke Fortran and $\mathrm{C}$ code). Also, Matlab/Mathematica/Maple allows export of results (both symbolic and graphic) in formats directly usable in TeX/LaTeX documents. R, a very popular statistics package, is a GNU licensed open source product.

TeX, the true and unsurpassed masterpiece of the art of computer programming, is faced with a strange fate: it somehow does not show up on the radar of promoters of IT for higher education. I believe this has a very simple explanation: TeX is free thanks to the generosity of Donald Knuth - and open source (moreover, the source code, with detailed comments and explanation, is published as a book; Knuth 1986b). It exists like the air that we breathe. For that reason TeX remains unadvertised and not promoted, and therefore unnoticed by university administrators who make decisions about the acquisition of IT products. Paradoxically, these are the same administrators who hold the purse strings and are apparently on the quest for the cheapest IT solutions. I conjecture that Moodle is also disadvantaged by being free, not promoted by vested commercial interests, and therefore invisible in the market.

We have to make free open source options visible - this will allow them to compete with commercial for-profit products. The problem is wider and concerns not only software and IT, but also textbooks. One of the referees of this paper suggested that an open-source model supports 'niche' disciplines better than a commercial model. This assessment is echoed by Gary Hall $(2008,42)$ :

\footnotetext{
Many publishers have decided to focus on introductions and readers for the relatively large (and so more profitable for their shareholders) first year undergraduate 'core course' markets, and hardly produce books for second-and-third-year students, let alone research monographs or even edited collections of original scholarship aimed at postgraduates and other researchers, at all.
}

From the next semester, I will be teaching one of my lecture courses using a GNU licensed textbook (Hefferon 2010). Besides pedagogical reasons, my decision is motivated by new functionality provided by open source textbooks: availability of source LaTeX files gives, for example, a possibility of global changes in the text, say a uniform change of notation over the entire textbook. In a properly written LaTeX source file, it is achieved by changing one line in the preamble. The need for change in notation rarely arises in most disciplines, but is quite common in mathematics. 
Availability of the source file resolves of number of issues of disability support - one line change allows a lecturer to change size, type, colour of fonts used, switch to the landscape mode, and so forth.

It is a social imperative of our challenging times: open source teaching suits publicly funded universities best. Because it is not promoted by commercial interests, it needs its champions. The textbook that I am planning to use finds an unexpected champion in Arnold Schwarzenegger. The book is endorsed by the Free Digital Textbook Initiative run by the California Learning Resources Network (http:// www.clrn.org/fdti/). The California Learning Resources Network is funded by the state of California. This state is experiencing financial difficulties, and the webpage of the Free Digital Textbook Initiative proudly displays a message from Governor of California Arnold Schwarzenegger:

This initiative will ensure our schools know which digital textbooks stand up to California's academic content standards - so these cost-effective resources can be used in our schools to help ensure each and every student has access to a world-class education.

Some of the existing repositories of open education resources (such as http:// www.oercommons.org/) and programmes for their development (such as the one run by HEFCE and JISC: http://www.jisc.ac.uk/oer) are still not sufficiently representative and not sufficiently selective. A systematic peer review is badly needed; perhaps it can be provided by greater involvement of subject specialists and their learned societies.

\section{Shopping list}

Mathematicians do not want to work in isolation from the rest of the IT learning community; there are a number of issues (like support to users with disabilities) that need a coordinated effort.

Here is a brief list of our concrete wishes. It was suggested by my colleagues who read earlier versions of my notes. Any help and advice from the IT learning community would be warmly appreciated.

In VLEs, we need support for, and interfacing with, Matlab, Mathematica, Maple, SPSS, R: symbolic input and output in Matlab, Mathematica, Maple; import of mathematics graphics produced by these packages; in SPSS and R - input and output of data files, import of tables.

As already explained, VLEs are unusable in mathematics learning and teaching if they do not support TeX/LaTeX. One of the benefits cited for VLEs is the ability for students to engage in discussions. They cannot do this if we have barriers to getting mathematics into a machine.

Provision for visually impaired students remains a serious problem. Screen readers do not work with mathematics.

Online computer-aided assessment is a big issue for those of us that want to formatively assess $350+$ size classes without using very bland questions. In particular, assessment systems should allow easy and unconstrained entry of mathematical formulae and be able to interpret their meaning. Some obstacles to that are discussed in Sangwin (2006).

Last but not least - the role and status of free and/or open source software, courseware and textbooks deserve a thorough discussion. 


\section{Acknowledgements}

Needless to say, all opinions expressed here are those of the author and no-one else. The author is grateful to the anonymous reviewers for their feedback. This article was first published in the Association for Learning Technology Online Newsletter (Issue 20, 11 August 2010, ISSN 1748-3603), reproduced here with minor amendments. Copyright of this paper remains vested with the individual authors or their employer and is licensed for use with a Creative Commons 'Attribution Non-Commercial-No Derivative Works 2.0 UK: England \& Wales licence'.

\section{Notes}

1. A list of available learning resources based on Matlab - and far from being complete - can be found online (http://www.mathworks.com/matlabcentral/linkexchange/?term=tag: "mathematics").

2. An earlier version of Cinderella can be downloaded for free (http://cinderella.de/tikiindex.php?page $=$ Download + Cinderella $+1.4 \& b l)$.

3. GeoGebra is free and open source (http://www.geogebra.org/cms/).

4. GAP - Groups, Algorithms, Programming - a System for Computational Discrete Algebra (http://www.gap-system.org//).

\section{References}

Association for Learning Technology. 2010. Learner acceptance of on-line learning and e-learning. http://wiki.alt.ac.uk/index.php/Learner_acceptance_of_on-line_learning_and_ e-learning.

Barker-Plummer, D., J. Barwise, and J. Etchemendy. 2008. Tarski's World. Chicago: University of Chicago Press.

Barwise, J., and J. Etchemendy. 1993. The language of first-order logic: Including the IBMcompatible Windows version of Tarski's World 4.0. Cambridge: Cambridge University Press.

Barwise, J., and J. Etchemendy. 1998. Computers, visualization, and the nature of reasoning. In The digital phoenix: How computers are changing philosophy, ed. T.W. Bynum and J.H. Moor, 93-116. London: Blackwell.

Barwise, J., and J. Etchemendy. 2003. Language, proof and logic. Stanford: CSLI Publications. Distributed by University of Chicago Press.

Bass, H. 2005. Mathematics, mathematicians, and mathematics education. Bulletin of the American Mathenatics Society 42, no. 4: 417-30.

Boolos, G. 1990. Review of Jon Barwise and John Etchemendy, Turing's World and Tarski's World. Journal of Symbolic Logic 55: 370-1.

Chevallard, Y. 1985. La transposition didactique - Du savoir savant au savoir enseigné. Grenoble: La Pensée sauvage.

Comte, A. 1852. Catéchisme positivist.

Goldson, D., and S. Reeds. 1993. Using programs to teach logic to computer scientists. Notices of the American Mathematics Society 40, no. 2: 143-8.

Hall, G. 2008. Digitize this book! The politics of new media, or why we need open access now. Minneapolis: University of Minnesota Press.

Hefferon, J. 2010. Linear algebra. ftp://joshua.smcvt.edu/pub/hefferon/book/book.pdf.

Hodges, W. 1989. Review of J. Barwise and J. Etchemendy, Tarski's World and Turing's World. Computerised Logic Teaching Bulletin 2, no. 1: 36-50.

Knuth, D.E. 1979. TeX and Metafont: New directions in typesetting. Stanford: Digital Press, and American Mathematical Society.

Knuth, D.E. 1986a. The TeXbook. Reading, MA: Addison-Wesley.

Knuth, D.E. 1986b. TeX: The program. Reading, MA: Addison-Wesley.

Knuth, D.E. 1990. 3:16 Bible texts illuminated. Middleton, WI: A-R Editions.

Knuth, D.E. 1999. Digital typography. Reissue ed. Cambridge: Cambridge University Press.

Lamport, L. 1985. Latex - A document preparation system - User's guide and reference manual. Reading, MA: Addison-Wesley.

Lawrence, R. 2003. Maths = typography? TUGboat 24, no. 2: 165-8. 
London Mathematical Society. 2010. Teaching position statement on mathematics degrees, their teaching and assessment. http://www.lms.ac.uk/policy/2010/teaching_position_ statement.pdf.

Morison, E. 1951. First principles of typography. Cambridge: Cambridge University Press.

National Union of Students. 2010. Student perspectives on technology - demand, perceptions and training needs. Report to HEFCE by NUS. http://www.hefce.ac.uk/pubs/rdreports/ 2010/rd18_10/rd18_10.pdf.

Neubüser, J. 1993. An invitation to computational group theory. Invited talk at the conference 'Groups St Andrews' at Galway 1993. http://www.gap-system.org/Doc/Talks/cgt.dvi and PostScript: http://www.gap-system.org/Doc/Talks/cgt.ps.

Sangwin, C. 2006. Assessing elementary algebra with STACK. http://www.open.ac.uk/cetlworkspace/cetlcontent/documents/4607d31d634fd.pdf.

Schwartz, J.L., M. Yerushalmy, and B. Wilson, eds. 1993. The geometric supposer: What is it a case of? Hillsdale, NJ: Lawrence Erlbaum Associates.

Shin, S.-J. 2004. Heterogeneous reasoning and its logic. The Bulletin of Symbolic Logic 10, no. 1: 86-106. 